\title{
TRABALHO, FRONTEIRA E MIGRANTES BOLIVIANOS NA CIDADE DE CORUMBÁ/MS: UMA ANÁLISE À LUZ DA CONSTITUIÇÃO FEDERAL DE 1988 E DO DIREITO AO PLENO EXERCÍCIO DA CIDADANIA
}

WORK, FRONTIER AND MIGRANTS IN BOLIVIAN CORUMBÁ CITY/MS: A REVIEW IN LIGHT OF THE CONSTITUTION OF 1988 AND THE FULL EXERCISE OF CITIZENSHIP

Marco Antônio Rodrigues

Pós-Graduado em Teoria e Filosofia do Direito pela PUC-Minas

Andréa Lúcia Cavararo Rodrigues

Bacharel em Ciências Sociais pela UFMS

Luciani Coimbra de Carvalho

Professora Adjunta da FADIR-UFMS - Coordenadora da Pesquisa

Submissão em 04.05.2016

Aprovação em 16.05.2016

DOI: http://dx.doi.org/10.21671/rdufms.v1i2.1728

Resumo: 0 presente artigo tem por objetivo apresentar os resultados do plano de trabalho intitulado "ANÁLISE DA DINÂMICA DO FLUXO MIGRATÓRIO NA FRONTEIRA BRASILEIRA CORUMBÁ/ PUERTO QUIJARRO E SUAS CONSEQUÊNCIAS SOBRE A ESFERA DE DIREITOS DA PESSOA HUMANA", integrante da proposta de PIBIC/CNPq vigente de agosto de 2015 a julho de 2016. A pesquisa analisou o fluxo migratório na fronteira anteriormente citada, analisando esse fenômeno social na esfera dos direitos fundamentais da pessoa humana e no âmbito social. 0 projeto de pesquisa foi desenvolvido por meio da pesquisa bibliográfica, bem como do trabalho de campo por meio da observação participativa, onde foram obtidos dados relevantes no campo social e jurídico. Como resultado da pesquisa, verificou-se que as leis brasileiras são insuficientes para abranger as espe- 
cificidades do tema proposto, chegando-se à conclusão de que o fenômeno migratório e a esfera de direitos do migrante estão em dissonância no que tange à efetividade dos direitos trabalhistas, evidenciando-se a necessidade de maior discussão para propositura de possíveis alterações em nosso ordenamento jurídico de forma a se abranger o empreendedorismo como ferramenta eficaz no acesso do migrante à cidadania.

Palavras-Chave: Migração nas Fronteiras; Fenômeno Migratório; Direitos da Pessoa Humana; Trabalho; Empreendedorismo.

\begin{abstract}
This article aims to present the results of the work plan entitled "ANALYSIS OF MIGRATION FLOW DYNAMICS IN BRAZILIAN FRONTIER CORUMBÁ / Puerto Quijarro AND ITS CONSEQUENCES ON THE BALL RIGHTS OF HUMAN PERSON", a member of the proposed PIBIC / current CNPq August 2015 to July 2016. The research analyzed the migratory flow in the border previously mentioned, analyzing this social phenomenon in the sphere of fundamental rights of the human person and in the social sphere. The research project was developed through bibliographical research and fieldwork by participant observation, which were obtained relevant data on social and legal field. As a result of the research, it was found that Brazilian laws are insufficient to cover the specifics of the proposed theme, coming to the conclusion that the phenomenon of migration and migrant rights sphere are in dissonance with respect to the effectiveness of labor rights, demonstrating the need for further discussion for bringing possible changes in our legal system in order to include entrepreneurship as an effective tool in the access of migrants to citizenship.
\end{abstract}

Keywords: Migration in the Borders; Migratory Phenomenon; Human Rights; Job; Entrepreneurship.

SUMÁRIO: 1. Introdução; 2. Desenvolvimento; Conclusão; Referências.

\title{
1. INTRODUÇÃ̃o
}

A pesquisa se propôs, através do estudo bibliográfico, documental e de campo, efetuar a análise da questão do fluxo migratório e alguns dos seus desdobramentos na fronteira de Mato Grosso do Sul, em especial as suas dinâmicas e modalidades.

A abordagem do campo social, histórico e jurídico teve como foco os grupos populacionais com grande vulnerabilidade, caracterizados por sua procedência geográfica, sejam brasileiros ou, em especial, os bolivianos que migraram e vivem na cidade de Corumbá/MS.

A metodologia buscou as modalidades e técnicas de pesquisa de levantamento de dados e informações que melhor se adequaram aos objetivos buscados pela proposta orientada nos planos de trabalho.

Como marco teórico inicial, as fronteiras serão zonas de interpenetração e, ao mesmo tempo, zonas de separação, sendo, nos dizeres de GABAGLIA (1916), "arenas de lutas contínuas entre os elementos de fusão e os elementos de disjunção, daí o caráter original e estranho que oferecem". 
Segundo LUSSI e DURAND (2015, p.46) "as mobilidades que permeiam a vida das pessoas e da sociedade atualmente são um modus vivendi que a globalização introduziu e dos quais a migração não é mais que uma de suas formas".

Os fluxos migratórios passaram a ser vistos não mais como fluxos bilaterais e com prevalência unidirecional, mas como realidades transnacionais, incluindo deslocamentos, atividades e espaços transnacionais, incluindo-se a gestão de bens, serviços e variadas formas de comunicação.

0 ponto central é que, mais do que pensar em migrantes como pessoas que nasceram em um país e agora se encontram em outro, o transnacionalismo sugere que se fale em transmigrantes, como uma mudança de perspectiva a partir da qual se olha, se lê e se interpreta a realidade da mobilidade humana e seus atores. $^{2}$

Também chamados labour migration ou migrations de travail, os fluxos migratórios que não têm como principal causa desencadeadora motivos de força maior como guerras ou desastres naturais, têm sido considerados tradicionalmente migrações econômicas.

Ainda segundo LUSSI e DURAND (2015), nas décadas de 1960 e 1970, economistas adaptaram a teoria clássica de Adam Smith, desenvolvendo a teoria neoclássica da migração, que tem uma versão macroeconômica e uma microeconômica. Esta tem foco nos indivíduos que agiriam no mercado de trabalho como atores racionais que decidem pela migração com base em cálculos claros e exatos de custo-benefício. Em sua versão microestrutural, esta teoria considera que os indivíduos decidem racionalmente pela migração, porque o cálculo do custo-benefício os leva a esperar um retorno final positivo, geralmente monetário, do movimento migratório.

Para LUSSI e DURAND (2015), esta perspectiva considera que o capital humano pode ser sacrificado pelo não reconhecimento ou pela falta de possibilidade real de acesso ao mercado de trabalho segmentado pelas economias capitalistas. Por sua vez, as possibilidades de valorização do capital humano se reduzem, normalmente, a experiências trabalhistas em setores do mercado de trabalho inferiores ao perfil que tais profissionais ocupavam antes da migração.

A teoria do duplo mercado de trabalho desenvolve-se como um modelo macroeconômico. Este postula que a migração internacional é o resultado de uma necessidade permanente de trabalhadores estrangeiros, inerente à estrutura econômica dos países desenvolvidos. Trata-se de uma demanda estrutural, sustentada por uma série de fatores economi- 
camente relevantes: salários, hierarquia profissional, desinteresse dos trabalhadores locais para certos trabalhos, organização dos diferentes setores de trabalho e sua relação com o capital, dentre outros aspectos. Esta teoria enfatiza que na origem da migração estão os fatores estruturais das modernas teorias capitalistas, as quais incluem contradições estruturais que afetam o mercado de trabalho onde vão se inserir os migrantes. Tais contradições são a forte demanda por trabalho não qualificado e possivelmente irregular, o trabalho informal e sem alguma segurança ou garantia, a implícita aceitação de migrantes irregulares onde a exploração trabalhista barateia os custos e a indústria da migração para o benefício de contrabandistas e traficantes de seres humanos (LUSSI; DURAND, 2015, p. 86).

A quantidade de bolivianos e demais atores que migram para a cidade de Corumbá-MS, ou apenas passam por ela, com destino à cidade de São Paulo e outras capitais brasileiras, todos os anos, torna-se uma questão importante para os Estados, principalmente por conta das distorções políticas e sociais, além das diferenças culturais que representam obstáculos ao processo de integração desses indivíduos às sociedades nacionais dos países que os recebem, gerando pobreza e exclusão social.

De acordo com AGUILERA URQUIZA (2010, p.56), é frequente em nossa sociedade, como em outras tantas, a visão/postura etnocêntrica, na qual uma cultura é tida como superior e as outras culturas como inferiores, sendo julgadas e explicadas como inadequadas. A diferença não está somente na cultura, mas sim em como nos encontramos nas posições sociais, nas diferenças de poder, nas quais um subordina o outro; uma relação de dominados e dominantes. Esta visão etnocêntrica está fundada em uma visão de mundo universal, de linguagem única, superior e melhor, de imposições e verdades absolutas, nas quais o desejo do colonizador foi de concretizar a unificação dos povos e da cultura.

Ao abordar os efeitos da globalização diante dos países periféricos, Milton Santos destaca uma das consequências da economia globalizada: as novas pobrezas.

De acordo com SANTOS (2001, p. 35):

0 último período, no qual nos encontramos, revela uma pobreza de novo tipo, uma pobreza estrutural globalizada, resultante de um sistema de ação deliberada. Examinando o processo pelo qual o desemprego é gerado e a remuneração do emprego se torna cada vez pior, ao mesmo tempo em que o poder público se retira das tarefas de proteção social, é lícito considerar que a atual divisão "administrativa" do trabalho e a 
ausência deliberada do Estado de sua missão social de regulação estejam contribuindo para uma produção científica, globalizada e voluntária da pobreza. Agora, ao contrário das duas fases anteriores, trata-se de uma pobreza pervasiva, generalizada, permanente, global. Pode-se, de algum modo, admitir a existência de algo como um planejamento centralizado da pobreza atual: ainda que seus autores sejam muitos, o seu motor essencial é o mesmo dos outros processos definidores de nossa época. A pobreza atual resulta da convergência de causas que se dão em diversos níveis, existindo como vasos comunicantes e como algo racional, um resultado necessário do presente processo, um fenômeno inevitável, considerado até mesmo um fato natural.Alcançamos, assim, uma espécie de naturalização da pobreza, que seria politicamente produzida pelos atores globais com a colaboração consciente dos governos nacionais e, contrariamente às situações precedentes, com a convivência de intelectuais contratados - ou apenas contratados - para legitimar essa naturalização. Nessa última fase, os pobres não são incluídos nem marginais, eles são excluídos. A divisão do trabalho era, até recentemente, algo mais ou menos espontâneo. Agora não. Hoje, ela obedece a cânones científicos - por isso a consideramos uma divisão do trabalho administrada - e é movida por mecanismos que traz consigo a produção das dívidas sociais e a disseminação da pobreza numa escala global. Saímos de uma pobreza para entrar em outra. Deixa-se de ser pobre em um lugar para ser pobre em outro. Nas condições atuais, é uma pobreza quase sem remédio, trazida não apenas pela expansão do desemprego, como, também, pela redução do valor do trabalho. É o caso, por exemplo, dos Estados Unidos, apresentado como o país que tem resolvido um pouco menos mal a questão do desemprego, mas onde o valor médio do salário caiu. E essa queda do desemprego não atinge igualmente toda a população, porque os negros continuam sem emprego, em proporção talvez pior do que antes, e as populações de origem latina se encontram na base da escala salarial.

\section{Para Brettel \& Hollifield (2000 apud SANTOS 2010):}

As várias formas como o tema migração tem sido tratado na literatura científica por antropólogos, historiadores, demógrafos, sociólogos, economistas, cientistas políticos e especialistas em direito. Os autores ressaltam a necessidade de se desenvolverem trabalhos com maior interdisciplinaridade e destacam pontos nos quais as questões e abordagens propostas por cada um destes ramos do conhecimento se aproximam dos outros. Brettel \& Hollifield (2000) propõem que sejam construídas "pontes" entre as disciplinas, ressaltando que já existe um bom intercâmbio entre algumas destas, havendo, entretanto, uma necessidade de 
que algumas disciplinas sejam incorporadas na discussão de temas tratados quase exclusivamente por outras.

\section{DesenVolvimento}

Com base nas perspectivas teóricas apresentadas, este trabalho atenderá aos objetivos da pesquisa dentro de um contexto interdisciplinar, perfazendo um breve diálogo entre as ciências que abrangem o tema da migração, além de analisar a situação do fluxo migratório na fronteira brasileira Corumbá/Puerto Quijarro e sua influência sobre a esfera de direitos da pessoa humana, analisando os fatos sob uma ótica não somente jurídica, mas com uma ampliação da pesquisa, de modo a buscar uma pré-compreensão do tema no tocante à realidade atual do fenômeno migratório na cidade de Corumbá/MS, e sua influência direta na esfera jurídica e social do migrante que passa ou se estabelece em Corumbá/MS.

Para contextualizar o tema no tocante à esfera de direitos, na primeira pesquisa de campo foi feita visita à Prefeitura Municipal de Corumbá, com ida à Secretaria de Infraestrutura, que informou sobre a existência de um possível "reduto" na cidade, com grande concentração de bolivianos, localizado na comunidade chamada Cristo Redentor, além de prestar esclarecimentos quanto à política social feita pela prefeitura em prol das comunidades carentes e para pessoas de baixa renda e em situação de vulnerabilidade, independentemente de sua origem ou nacionalidade.
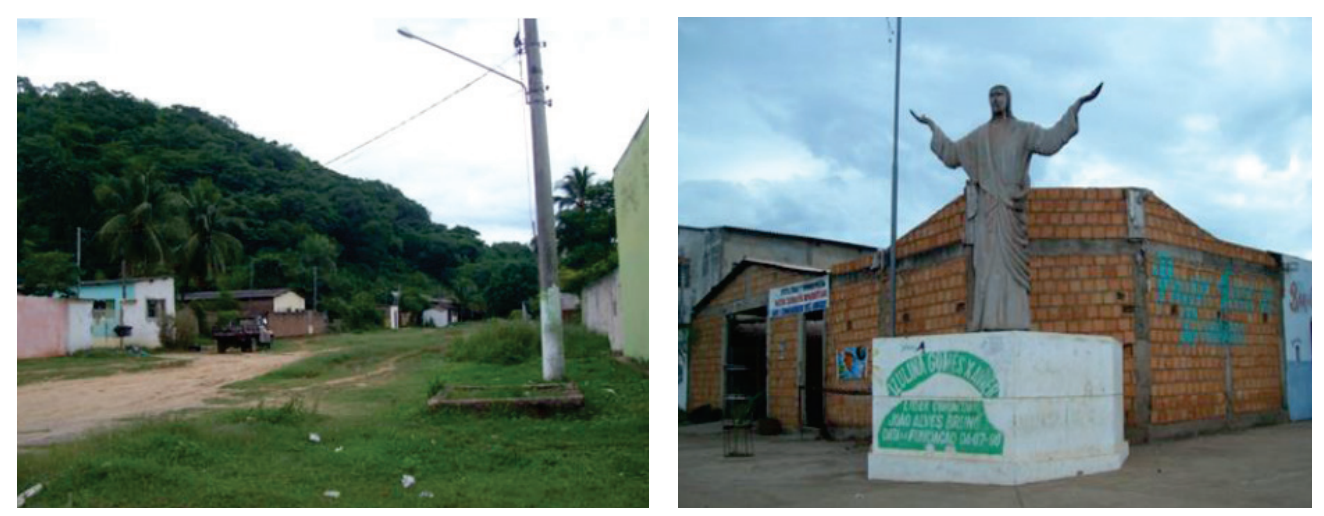

Figuras 1 e 2 - Comunidade Cristo Redentor (arquivo pessoal)

Segundo a Prefeitura de Corumbá, os bolivianos, ao atravessarem a fronteira em busca de trabalho, obtêm um permiso para poderem circular livremente e trabalhar no Brasil. Foi informado que após cinco anos de trabalho regular no Brasil por meio do permiso, os bolivianos adquirem o direito a se naturalizar. 
Conforme a Secretaria de Patrimônio Cultural e Habitação, existem políticas de recadastramento e acompanhamento das famílias residentes na área do "antigo lixão", onde supostamente se encontrariam a maior concentração de bolivianos em situação de pobreza ou recém chegados à cidade.

De acordo com a Receita Federal em Corumbá/MS, o Cadastro de Pessoa Física (CPF) é concedido para os bolivianos que trabalham no Brasil a fim de que possam abrir conta corrente para recebimento de salários e demais benefícios. Segundo o órgão, o CPF é concedido de forma vitalícia aos mesmos, não importando se eles permanecerão, ou não, no Brasil.

Com base em informações da Polícia Federal, há grande quantidade de pessoas que atravessam a fronteira diariamente, não só da nacionalidade boliviana, mas de diversas nacionalidades, até mesmo russos, australianos, angolanos, dentre outros, com destino a São Paulo e outras grandes capitais como Rio de Janeiro e Minas Gerais.

A Polícia Federal (PF) ressaltou que a condição de trabalho escravo se evidencia em virtude das condições precárias de trabalho a que os bolivianos se submetem nas fábricas, sem direitos trabalhistas, e com jornadas excessivas de trabalho.

Além disso, os bolivianos empregados nas confecções são compulsados a trabalhar sem receber qualquer remuneração nos três primeiros meses em que são admitidos para pagar as despesas de custeio com seu translado da Bolívia até o Brasil.

Com efeito, são descontadas dos seus salários todas as despesas com alimentação e hospedagem. Mesmo assim, acentuou a Polícia Federal, os bolivianos preferem se submeter a esse sistema de exploração devido à extrema pobreza e falta de oportunidades havidas do lado de lá da fronteira, dando margem a quadrilhas especializadas em exploração de pessoas, tráfico de drogas, contrabando e demais delitos. A PF também informou que há quadrilhas especializadas na falsificação de documentos para facilitar o ingresso dos bolivianos e a sua permanência no Brasil.

Para uma melhor visualização e contextualização do problema, são apresentados os gráficos a seguir, relativos ao espaço amostral de 66 (sessenta e seis) entrevistados no período da pesquisa: 
PERFIL DOS BOLIVIANOS QUE ATRAVESSAM A FRONTEIRA

1. QUANTO AO SEXO (em percentuais)

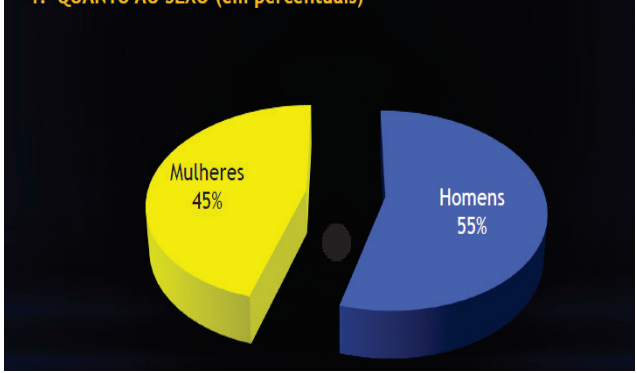

PERFIL DOS BOLIVIANOS QUE ATARVESSAM A FRONTEIRA

1. QUANTO A FAIXA ETÁRIA (em números absolutos)

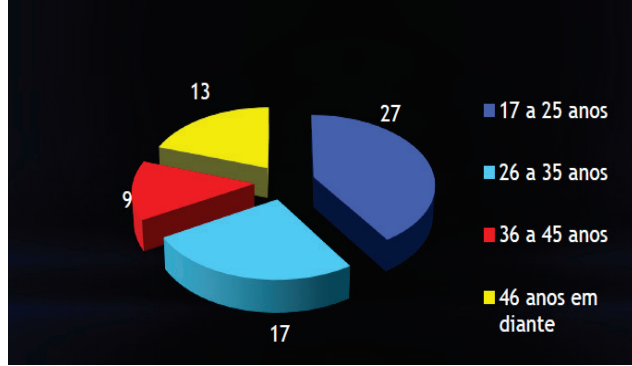

PERFIL DOS BOLIVIANOS QUE ATARVESSAM A FRONTEIRA

1. QUANTO AO DESTINO

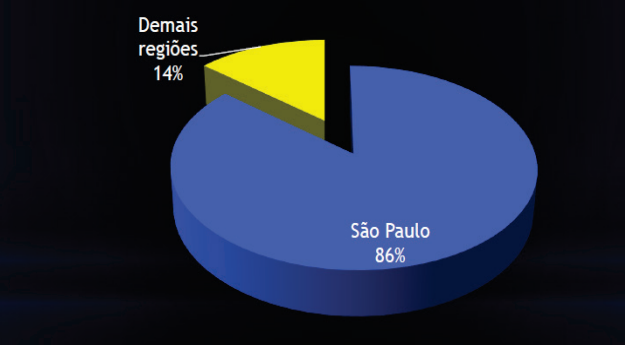

Análise de dados obtidos por meio de entrevistas no período da pesquisa na fronteira Corumbá(BRA)/Puerto Quijarro(BOL). (Arquivo Pessoal)

A Secretaria de Assistência Social da Prefeitura de Corumbá enfatizou o atendimento igualitário dado a todos os cidadãos, mas fez ressalva quando se tratou de abordar os bolivianos. Isto porque há um fenômeno que ocorre com as mulheres bolivianas que cruzam a fronteira em busca de atendimento médico, pois elas buscam ter seus filhos no Brasil a fim de garantir a assistência brasileira, que é gratuita. Constatou-se que os direitos existem e são, na medida do possível, atendidos e respeitados.

Há programas sociais da Prefeitura voltados à educação continuada, em que os professores são incentivados a aprender o idioma espanhol a fim de poder atender à demanda de alunos bolivianos que cruzam a fronteira em busca de melhores condições de ensino.

O Sr. André Menacho, boliviano, encontra-se no Brasil há mais de trinta anos, e após uma entrevista informal quanto à chegada dele e de seus familiares no Brasil, bem como o Sr. Anisio Guató, prestaram diversas informações que serviram de suporte à pesquisa na área legal e social, onde foi possível constatar como se deu a acolhida deles em Corumbá. 
Diante dos fatos observados, constata-se a fragilidade das normas quanto à sua efetiva aplicação às pessoas que passam pela fronteira, sejam elas bolivianas ou de outras nacionalidades. Tal ocorrência leva a diversas implicações quanto ao direito de atendimento na rede de saúde brasileira, bem como na obtenção de outros direitos que possam assegurar o princípio da dignidade humana.

Como reflexo da fragilidade mencionada, pode ser citado o incidente ocorrido no Centro Boliviano de Corumbá, que era um local de ambientação social não somente de bolivianos, mas de acolhimento de pessoas das mais variadas localidades, reunindo-se em torno de atividades comerciais e das trocas de informações e se revestindo em um local rico pela diversidade, mas que fora fechado repentinamente por decreto municipal, refletindo "o caráter contrastivo da identidade étnica e seu forte teor de 'oposição' com vistas à afirmação individual ou grupal" (Cardoso de Oliveira apud Costa, 2015).

O que se observa dentre os povos que passam pela fronteira, e os que permanecem no Brasil, é um ponto comum: a busca de trabalho.

Todavia, a busca de trabalho deve ser pautada em ações que permitam ao estrangeiro atingir a meta. Infelizmente, a maioria dos bolivianos que passam pela fronteira irão se dedicar à informalidade, principalmente as mulheres.

A tradicional feira de domingo realizada em Corumbá/MS permite visualizar a grande quantidade de bolivianos que se dedicam ao comércio e que devido à sua expulsão em virtude do fechamento do Centro Boliviano, percebe-se que mais de metade das barracas da feira é administrada pelos bolivianos, em geral mulheres.

A ausência de um centro comercial ou espaço cultural onde o migrante possa se expressar e viver a sua realidade permite concluir que a esfera de direitos naquela região ainda está longe de se concretizar, pois o fechamento do local embaraçou a vida de muitos migrantes que eram legalizados, sendo uma atitude drástica e em total descompasso com a previsão contida na Carta Magna de 1988.

A tradicional Festa do Migrante na Pastoral do Migrante Nossa Senhora de Fátima representa um momento de integração dos migrantes que chegam à Corumbá em situação de grande vulnerabilidade social, oportunizando a sua inserção na comunidade por meio do contato inicial com os brasileiros. A festa também possui o caráter de acolhimento do migrante boliviano em nosso território. 

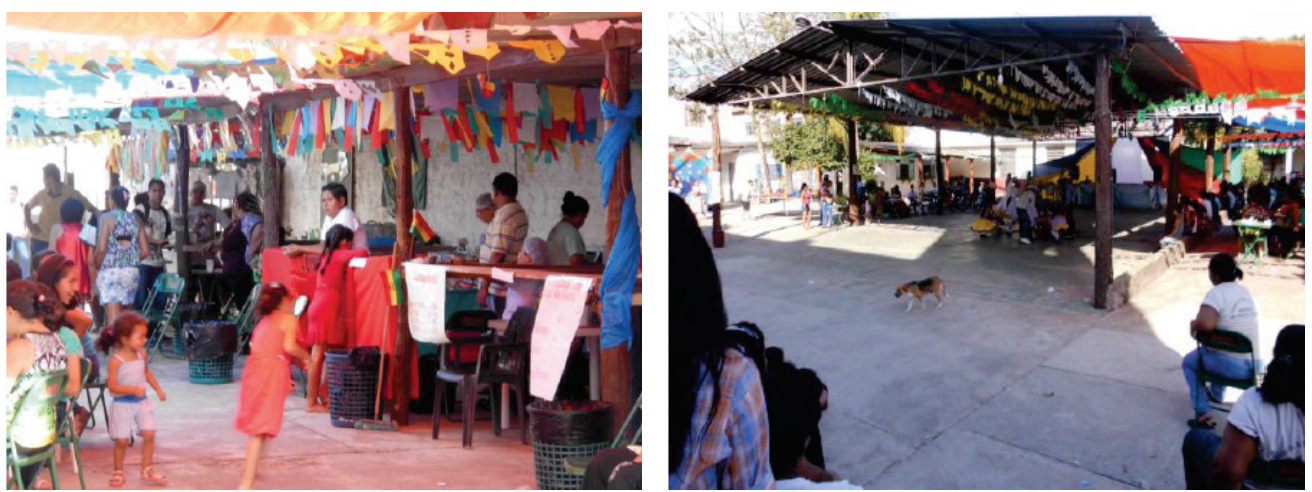

(Fonte: arquivo pessoal)

De acordo com o Padre Marco Antonio, ao discorrer sobre o atendimento do migrante em Corumbá, são patentes as dificuldades encontradas para a efetiva aplicação dos direitos da pessoa humana na localidade.

Segundo o entrevistado, há muitas exigências documentais para que o migrante seja atendido em postos de saúde, bem como tenha acesso aos serviços básicos do cidadão a fim de que lhe seja garantido trabalho e acolhida na cidade de Corumbá.

0 trânsito de pessoas pela fronteira, bem como a permanência dos migrantes do lado de cá são facilitadas desde que não sejam reclamados direitos, sejam eles os mais básicos. Em caso contrário, são colocados vários empecilhos para que o migrante atravesse ou permaneça no território brasileiro.

Outro dado importante encontrado pela pesquisa foi sobre as possibilidades de travessia de bolivianos para o Brasil em outras localidades, como Letícia, próximo a Porto Velho/RO e pelo Estado do Acre.

A travessia ilegal por cada uma dessas cidades possui um preço: pela cidade colombiana de Letícia, que faz fronteira com Tabatinga (AM), em torno de U\$\$ 500 (quinhentos dólares), pela cidade de Brasiléia, no Acre, que é cortada pela rodovia BR-317 (liga o Acre ao Pacífico), em torno de U\$\$ 800 (oitocentos dólares) e por Corumbá/MS, o valor gira em torno de U\$ 2000 (dois mil dólares).

De acordo com a Pastoral do Migrante de Corumbá, há famílias bolivianas que vivem em situação de extrema pobreza, mas preferem ser ajudadas pelos minguados recursos da pastoral do que se registrarem junto ao Estado, haja vista as exigências legais para permanência, bem como o risco de serem expulsas do país devido à sua situação de ilegalidade. 
São acolhidas pela pastoral diversas pessoas, procedentes de diversas partes do mundo, libaneses, árabes, italianos, russos, e até senegaleses.

Conforme observado, a migração ainda é tratada como "caso de polícia" e de segurança nacional, relegando a área de Direitos Humanos e de Assistência Social ao segundo plano, haja vista as dificuldades encontradas pelo migrante serem inúmeras, e na hipótese de sua estada ser para o trato de assuntos triviais ou comércio informal, isso é tolerado pelo Estado brasileiro.

Observou-se que o cidadão boliviano, bem como qualquer migrante, possui imensos obstáculos para obter documentos que lhe garantam a sua cidadania e a sua estada legal no Brasil, a fim de que lhe seja garantido trabalho digno e assistência do Estado para as suas necessidades mais básicas, seja no tocante à saúde ou obtenção de documentos que possibilitem uma melhor convivência como cidadão.

Constatou-se por meio da pesquisa que a Lei Complementar no 128, de 19 de dezembro de 2008, bem como a Resolução no 78, de 13 de setembro de 2010 do Comitê Gestor do Simples Nacional (CGSN) apresentam de forma clara as condições e requisitos para que o cidadão brasileiro ou naturalizado venha a se tornar um microempreendedor individual, possibilitando que usufrua de todos os direitos inerentes a essa categoria, haja vista a feira de domingo possuir a maioria das barracas operadas por bolivianos, que pagam uma taxa de permanência ou ocupação do local sem que isso venha a reverter em qualquer direito para eles.

\section{ConCLUSÃo}

No tocante à esfera de direitos, pode-se constatar que há muitas informações contraditórias quanto à obtenção de documentos pelos bolivianos e sua permanência no Brasil.

Constatou-se um número considerável de famílias compostas apenas pela mulher, brasileira, e segundo informações do Centro de Referência de Assistência Social (CRAS), na maioria dessas famílias, o homem é boliviano e prefere se omitir para não sofrer discriminação e não se submeter ao processo administrativo de naturalização, avaliado em torno de $\mathrm{R} \$ 5.000,00$ (cinco mil reais) segundo o CRAS informou. Além disso, o boliviano, ao se submeter ao demorado processo de naturalização, nem sempre consegue emprego e mesmo assim sofre restrições devido à espera do resultado do processo, preferindo viver na clandestinidade.

A pesquisa constatou que há bolivianos que trabalham na construção civil do lado brasileiro e estão regularmente empregados, no entanto ao pleitearem seus direitos devem buscar a tutela do Ministério Público do Trabalho, pois há 
casos em que os direitos trabalhistas não são pagos e sendo estrangeiros o processo de busca dos direitos é extremamente dificultoso.

Nessa etapa, foi dada prioridade ao viés social da pesquisa e partiu-se da visualização in loco da realidade dos bolivianos e de suas famílias quando chegam ao Brasil em busca de melhores condições de vida e a confrontação dessa mesma realidade com o direito previsto e não aplicado, ou aplicado parcialmente. Espera-se que sejam encontradas soluções ou apresentadas propostas e novos modelos que consigam atender às expectativas desses cidadãos com vistas a se resolver possíveis lacunas existentes entre o direito e a realidade vivida por essas pessoas.

Entretanto, o que se observa dentre os povos que passam pela fronteira, e os que permanecem no Brasil, é a busca de trabalho e dignidade.

Infelizmente, a maioria dos bolivianos que passam pela fronteira irão se dedicar à informalidade, principalmente as mulheres.

Embora haja acordos diplomáticos e de cooperação entre o Brasil e a Bolívia, há nítida diferenciação entre os brasileiros e os bolivianos no que concerne à esfera de direitos. 0 avanço nessa discussão tem trazido inúmeros benefícios às populações que recorrem ao Brasil, seja como residência ou apenas com o fim de assistência social ou de saúde.

Malgrado a face obscura do trabalho escravo, e a ausência de leis que efetivamente tratem o caso da migração como um caso social, e não apenas entabulem o problema migratório como caso de polícia, o fluxo migratório dos bolivianos segue um padrão determinado, onde a maioria possui idade entre 25 e 35 anos, portanto em idade produtiva.

A cidade de Corumbá, por razões históricas, é um local de passagem de pessoas no sentido das grandes capitais brasileiras, e que se ressente por isso, haja vista a pessoa que atravessa a cidade não deixar absolutamente "nada" em contrapartida, apenas usando a localidade como descanso conforme o dizer dos corumbaenses.

Em outra ótica, não há restrições legais para que os migrantes que exercem suas atividades em território brasileiro possam se formalizar, aderindo ao microempreendedorismo por meio do cadastramento na Receita Federal, haja vista receberem CPF e documentação que permite o recolhimento de tributos e demais impostos ao Estado brasileiro, adquirindo amparo legal que permita o usufruto dos direitos conferidos aos brasileiros, como auxílio-doença, aposentadoria e demais direitos inerentes ao cidadão formalizado. Para amenizar as mazelas da legislação brasileira e o seu efetivo amparo aos migrantes, quem sabe o caminho não seria esse? 


\section{REFERÊNCIAS}

AGUILERA URQUIZA, A.H. Povos Indígenas no Brasil:a perspectiva da diversidade e autonomia. In: AGUILERA URQUIZA, A. H. et al. EDC - Seminários e perspectivas da diversidade e cidadania - Vol. I. Ed. Premier - UNICENTRO, 2010.

BRASIL. Constituição (1988) Constituição da República Federativa do Brasil. Brasília: Senado, 1988.

BRASIL. Lei no 6.815, de 19 de agosto de 1980. Diário Oficial da União, Brasília, 21 ago. 1980.

BRASIL. Decreto no 5.017, de 12 de março de 2004. Diário Oficial da União, Brasília, 15 mar. 2004.

BRASIL. Lei Complementar no 128, de 19 de dezembro de 2008. Diário Oficial da União, Brasília, 22 dez. 2008.

BRASIL. Ministério da Justiça: Relatório Mostra Avanços na Luta Contra o Tráfico de Pessoas. Brasília: MJ, 2014. Disponível em <http://www.justica.gov.br/noticias/relatorio-mostra-avancos-na-luta-contra-o-trafico-de-pessoas>. Acesso em 09 out. 2014.

BRASIL. Receita Federal do Brasil: Resolução CGSN no 78, de 13 de setembro de 2010. Brasília: RFB, 2010. Disponível em <http://www.receita.fazenda.gov.br/legislacao/resolucao/2010/CGSN/Resol78.htm>. Acesso em 10 jul. 2015.

BRASIL. Ministério da Saúde: Política de Enfrentamento ao Tráfico de Pessoas. Brasília: MS, 2014. Disponível em <http://bvsms.saude.gov.br/bvs/publicacoes/politica_enfrentamento_trafico_pessoas.pdf>. Acesso em 10 out. 2014.

BRETTEL, C. B.; HOLLIFIELD, J. F. (2000). Introduction. In:Migration Theory: Talking Across Disciplines.BRETTEL, C. B.; HOLLIFIELD, J. F. (Ed.). New York: Routledge, 2000. p.1-26.

CARDOSO DE OLIVEIRA, Roberto; BAINES, Stephen (Org.). Nacionalidade e Etnicidade em Fronteiras. Brasília: Editora UnB, 2005.

COSTA, Gustavo Villela Lima da. Os Bolivianos em Corumbá-MS: Conflitos e Relações de Poder na Fronteira.Rio de Janeiro, 2015. Disponível em <http://www.scielo.br/scielo. php?script=sci_arttext\&pid=S0104-93132015000100035>. Acesso em 27 de abril de 2016.

GABAGLIA, Fernando Raja. Fronteiras do Brasil. Disponível em <http:// archive.org/details/asfronteirasdobr00gaba>. Acesso em 09 set. 2014.

LUSSI, Carmen; DURAND, Jorge. Metodologia e Teorias no Estudo das Migrações. São Paulo: Paco Editorial, 2015.

SANTOS, Mauro Augusto dos. Migração: Uma revisão sobre algumas das principais teorias. Belo Horizonte: UFMG/Cedeplar, 2010.

SANTOS, Milton. Por uma outra Globalização: do pensamento único à Consciência Universal. São Paulo: Editora Record, 2001. 
